\title{
Article
}

\section{Tourist experience: The catalyst role of tourism in comforting melancholy, or not}

Christou, P. and Simillidou, Aspasia

Available at http://clok.uclan.ac.uk/31801/

Christou, P. and Simillidou, Aspasia (2020) Tourist experience: The catalyst role of tourism in comforting melancholy, or not. Journal of Hospitality and Tourism Management, 42 . pp. 210-221. ISSN 1447-6770

It is advisable to refer to the publisher's version if you intend to cite from the work. http://dx.doi.org/10.1016/j.jhtm.2020.01.007

For more information about UCLan's research in this area go to http://www.uclan.ac.uk/researchgroups/ and search for < name of research Group>.

For information about Research generally at UCLan please go to http://www.uclan.ac.uk/research/

All outputs in CLoK are protected by Intellectual Property Rights law, including Copyright law. Copyright, IPR and Moral Rights for the works on this site are retained by the individual authors and/or other copyright owners. Terms and conditions for use of this material are defined in the policies page.

\section{CLoK}

Central Lancashire online Knowledge www.clok.uclan.ac.uk

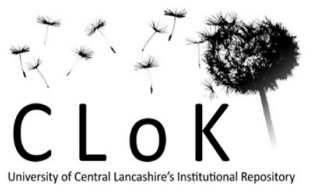




\section{Manuscript Details}

Manuscript number

Title

Short title

Article type
JHTM_2019_317_R1

Tourist experience: The catalyst role of tourism in comforting melancholy, or not

Tourism and Melancholy

Research Paper

\section{Abstract}

Although it cannot be interpreted as severe depression, melancholy has disquieted individuals and societies for millennia. This study explores the extent to which tourism can move beyond the formation of enjoyable experiences and become a source of comfort for melancholy. The present study reveals that tourism does not act as a panacea for melancholy. Nonetheless, it may substantially relieve the symptoms through a concurrent amalgam of pleasure and activity factors, distractions, and the seclusion choices it offers. The eagerness associated with an imminent leisure trip and the strength to fight challenges in the personal and social domains following a reviving travel experience are also imperative comforting dynamics. A relevant research agenda is proposed, and the managerial implications for how the tourism industry can secure comforting experiences are discussed.

\section{Keywords}

Taxonomy

Manuscript region of origin

Corresponding Author

Corresponding Author's Institution

Order of Authors

Suggested reviewers melancholy; depression; tourist experience; leisure; happiness

Social Sciences, Arts and Humanities

Europe

Prokopis Christou

Cyprus University of Technology

Prokopis Christou, Aspasia Simillidou

Alexis Saveriades, Anna Farmaki

\section{Submission Files Included in this PDF}

\section{File Name [File Type]}

Cover letter.docx [Cover Letter]

RESPONSE LETTER.docx [Response to Reviewers (without Author Details)]

Title Page.docx [Title Page (with Author Details)]

Manuscript (anonymous copy).docx [Manuscript (without Author Details)]

Figure 1.docx [Figure]

Figure 2.docx [Figure]

Figure 3.docx [Figure]

Table 1 (table of informants).docx [Table]

Table 2 (causes of melancholy).docx [Table]

Table 3 (travel characteristics).docx [Table]

Table 4 (Remedying tourism factors).docx [Table]

To view all the submission files, including those not included in the PDF, click on the manuscript title on your EVISE Homepage, then click 'Download zip file'. 
Dear Editor,

Thank you very much for allowing resubmission of our manuscript. You will notice that in our detailed response letter, we have addressed all comments made by the two reviewers. The manuscript reflects the changes made while the reference list has been updated and includes further studies, as requested by the reviewers.

Yours sincerely,

The authors 
November, 2019

\section{Response to reviewers' comments}

Thank you both very much for sharing your comments and concerns. In the light of your suggestions, the paper has been revised and the necessary changes, amendments and adjustments have been made. The changes and additions made to the paper are summarized below. Please note that the text in italics is drawn from the reviewers' reports.

\section{Reviewer \#1:}

This was certainly a manuscript that attempts to fulfil a clearly defined research gap. I enjoyed reading the manuscript.

Response: We are glad that you have enjoyed reading our paper. We hope that you will be pleased with the revised version of the manuscript.

1. In the abstract you mention that tourism does not act as a panacea for melancholy. But then your title for the paper seems to be suggesting that it is. The title should be reframed as....the catalyst role of tourism in comforting melancholy or not!

Response: Your point is valid. Therefore, we have embraced your suggestion and altered our title to reflect the study findings.

2. As you mentioned in the intro: these studies are deprived from the possibility of allowing in-depth elucidations...but elucidations of what?

Response: The sentence has been revised and now reads as: ... Elucidations of the tourism and depression nexus.

3. The intro lacks a definition of melancholy

Response: The introduction now includes a definition of melancholy.

4. A clearer identification of the research gaps and contribution of the study in the intro. Response: Please note that the introduction has been revised and both (that is, the gap and contribution of the study) have been strengthened. Please refer to the second paragraph, of the Introduction.

5. Literature review needs to have sub-titles to allow the reader to follow your thought process.

Response: You will now notice that the literature review has sub-titles.

6. Please explain how the data was analysed and provide a table showing how the data was coded, with axial coding and how themes were extracted.

Response: Thank you for your suggestion. Additional information is now included in the study methods section that address the data coding and analysis process. Please refer to sub-section 
3.3. Furthermore, in order to enable readers to comprehend the axial coding process that was adopted, a new diagram is now included that is based on the coding paradigm as suggested by Strauss \& Gorbin (1998). For your convenience, this is also presented below:

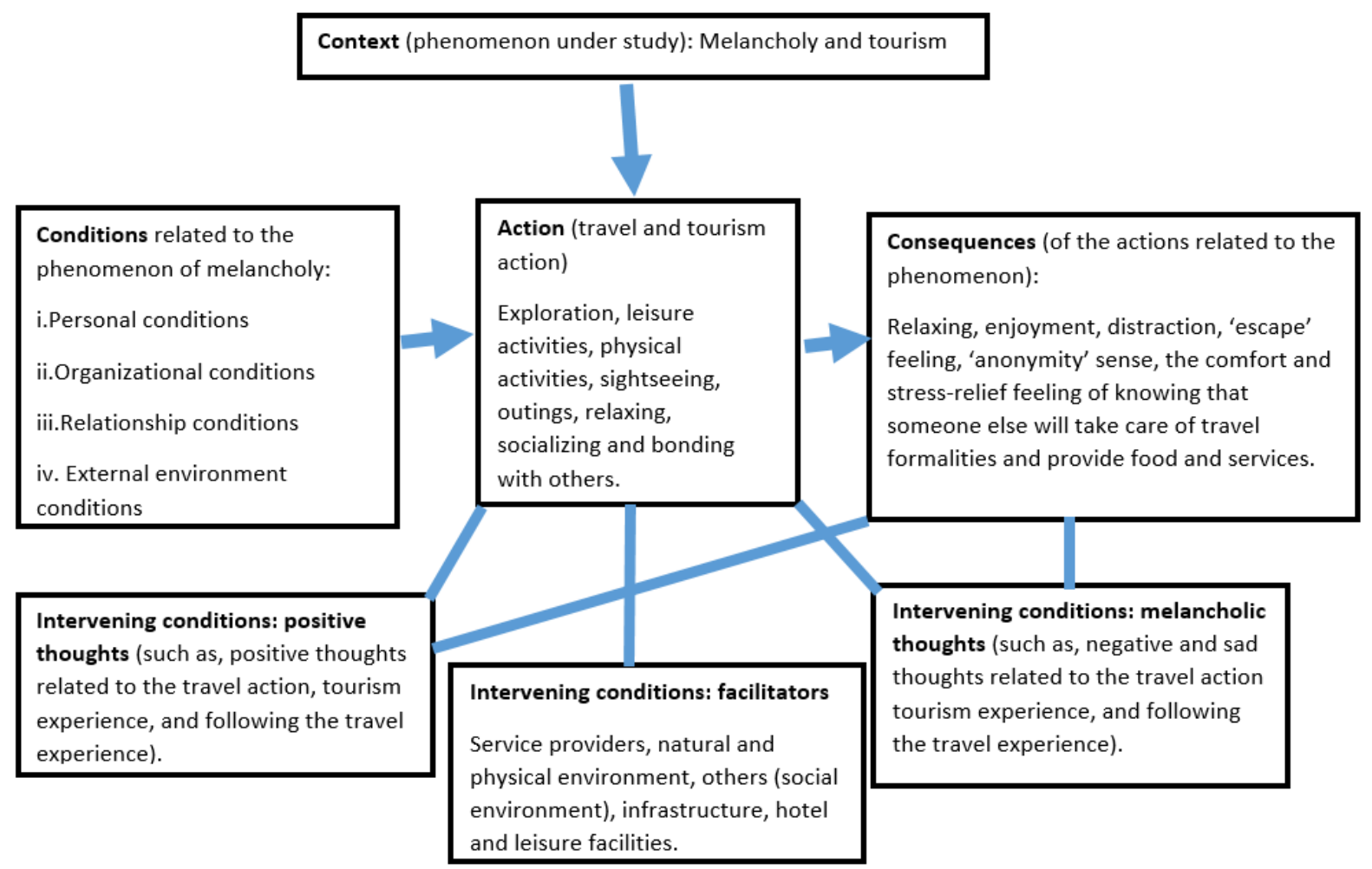

7. You refer to data saturation as the end of your sampling, please provide a justification from the literature as support for data saturation technique.

Response: Further justification is provided, supported by relevant literature, in the revised manuscript. Please refer to the first paragraph of section 3.3: Interview information, saturation and analysis of findings.

8. So what are the managerial implications of your findings - you have only 1 paragraph on this and why does your result matter for the industry?

Response: The managerial implications have been revised and enhanced with additional information in the newly formed section 7 of the manuscript, labelled as "Implications".

9. The manuscript does not follow the formatting guidelines for JHTM.

Response: Thank you for pointing this to us. As you will notice, the revised version now follows the formatting guidelines of JHTM (for example, the paper is divided into clearly defined and numbered sections).

Reviewer \#1, thank you once more for your comments and suggestions. 


\section{Reviewer \#2}

1. The use of a psychodynamic approach is noted in the manuscript. This is an important point that needs further discussion. What alternative approaches are possible? Why was the psychodynamic approach adopted? How does this affect the theory, methodology and analysis of the paper? Is the psychodynamic approach treated as a paradigm or as a body of theoretical knowledge? The review of the literature notes a series of research findings regarding depression. Are all of these papers from the psychodynamic approach? This point that the paper uses a psychodynamic approach is very important but this approach is not discussed. The literature review discusses

\section{Response:}

the various types of depression but there is no use of this in the analysis?

Thank you for your comments. In our attempt to keep the paper within a reasonable word limit, we failed to discuss this in detail. The psychodynamic approach was chosen as a comprehensive approach for understanding personal phenomena. In more detail, based on the psychodynamic approach, the literature review attempts to examine the concept of melancholy from different views and perspectives, such as, philosophical and medical. The manuscript uses studies from different disciplines, such as philosophical that conceivably (due to their philosophical nature), have not employed the psychodynamic approach. Even so, we had to include these differing perspectives to provide a holistic appreciation of the notion under investigation (in this case, melancholy). As you will notice below, we attempted to identify issues related to human drives and emotions, to fully comprehend the nexus of melancholy and tourism. Based on your reasonable points, we have added in the introductory phase of the paper new information regarding the psychodynamic approach. For your convenience, we are also delivering this below. Please note that the reference list has also been updated and now includes these studies:

This paper locates the construct of melancholy within a psychodynamic theoretical context (Borden, 2009), enabling readers to understand its idiosyncrasies and effects, as well as informing the need for further research on the topic. Psychodynamics have been used to examine different phenomena, such as the case of evil (Stone, 2016) anti-bullying (Schwartz, 2016), anti-Semitism (Ostow, 1996) and social networking (Balick, 2018). Though psychodynamics are used in the case of psychotherapy (Johansson, 2019; Gabbard, 2017; Driessen et al., 2015), in a broadest sense psychodynamic psychology emphasizes psychological forces that underlie human behavior and emotions and how they might relate to the experience of people. Such approach takes into consideration other disciplines, such as medical, social and spiritual, to allow comprehensive results to be obtained. "It [psychodynamic] cannot very well be limited to any one discipline... Only so can fully comprehensive research be maintained" (Guntrip, 1995, p.18). On one hand, this approach involved the search for deeper understandings of melancholy, based on a thorough review of different perspectives of the notion, and emergent empirical literature on its interpretations (Henry et al., 1994). On the other hand, according to the psychodynamic approach, it sought to identify how human functioning as based on the interaction of drives and forces (McLeod, 2017), pursued leisure traveling as a comforting means for melancholy, and how this behavior (of traveling), affected their emotional state.

Furthermore, please note that we added a sentence which links certain study questions with this approach (refer to: Study methods section- guiding questions). In response to your comment regarding the types of depression, please note that we now emphasize in our discussion that 
melancholy, although it is a state suffered, it may not be interpreted as "severe depression". Particularly, its differentiation with MDD (Major Depressive Disorder) is emphasized both in the literature review and the analysis.

2. The paper uses a qualitative approach but the discussion section makes causal claims "Even so, certain causes were found to be linked with age."

Response: In this case, we refer to 'causes of melancholy'. To avoid confusion, this is now clarified in our revised manuscript (refer to section 5).

3. The findings are discussed but their significance to the literature are not. The contribution of the paper to the study of depression and travel needs to be clearly identified. What is significant that has been found and why is it significant? Is the overall significance of this paper that it supports prior research? For example the following may be true but why is it significant? The present study reveals that tourism does not act as a panacea for melancholy. Nonetheless, it may substantially relieve the symptoms through a concurrent amalgam of pleasure and activity factors, distractions, and the seclusion choices it offers.

Response: You will notice that the significance of the study is further strengthened in the "Discussion and Conclusions" section. For instance, previous research has shown that tourism impacts favourably on the well-being of people, may act as a happiness booster, and contributes to the positive psychology of people. In the present study, it is emphasized that people may wrongfully pursue a leisure trip to comfort melancholic symptoms they may experience based on such long-heralded positive effects of tourism. However, this (travel behavior) may deprive from them the possibility of seeking professional help, or simply dealing with their problems while at their home setting, with the hope that a trip may "erase" such melancholic states. This outcome informs certain implications for destinations and resorts, as discussed in the section labelled as "implications".

4. The discussion and conclusion section introduce new data. This is not normal practice. Well, the holiday helps ... up until you get back to your routine and get back to work ... Just thinking about it demoralizes you. But I need to add that this wasn't the case when working in the UK, as the environment I was working in was very professional and positive [note: the interviewee now resides abroad]. I think external factors also have an impact on how long the "holidaymoon" lasts! (Sophie, 40-49, $U K)$.

Response: Indeed, this is not a normal practice. Hence, new information and representative quotes- as the one you refer to, have been shifted to the 'findings' section (please refer to section 4 and more specifically, subsections 4.2 and 4.3).

5. The significance or need for the following paragraph is not clear. "Of note is the fact that melancholy still troubles people, with its severe effects being evidenced from Biblical times; Cain, when punished to a life of wandering after the homicide of his brother, exclaimed in agony, "My punishment is greater than I can bear" (Genesis 4:13). A sculpture (by Mullins, c. 1899) of the fratricidal firstborn son of the Protoplasts in his melancholic state can be seen at the Glasgow Botanic Gardens."

Response: You are right. This paragraph served no particular purpose to the aim of the study. Thus, the abovementioned paragraph is not included in our revised version. 
6. Overall the paper needs to a major revision to strengthen the conclusions and emphasise their significance.

Response: Based on your suggestions, you will notice that we have revised the manuscript by adding additional information both in our introduction and conclusion sections to fortify the need and significance of the present study on the nexus of melancholy and tourism.

Reviewer \#2, thank you once more for your comments and suggestions. 
Tourist experience: The catalyst role of tourism in comforting melancholy, or not

Authors: Christou, P.\& Simillidou, A.

\section{Prokopis A. Christou, PhD (corresponding author)}

Department of Hotel and Tourism Management, Cyprus University of Technology, 30 Archbishop Kyprianou Str. 3036 Lemesos, Cyprus. Tel.: ++357 25002430 Email: Prokopis.christou@cut.ac.cy.

Prokopis Christou's main research interests include the sociology and psychology of tourism, focusing specifically on the consumption and meaning of touristic experiences in contemporary society. He has published research and conceptual papers in leading academic tourism journals, such as Annals of Tourism Research and Tourism Management.

\section{Aspasia, Simillidou, PhD}

School of Business \& Management, University of Central Lancashire- Cyprus, 12-14 University Avenue, Pyla, Larnaka, Cyprus. Tel.: +357 24694007. Email:

ASimillidou@uclan.ac.uk.

Aspasia Simillidou is the Course Leader of Tourism and Hospitality Master studies at the University of Central Lancashire, Cyprus. Her research interests include psychological issues, such as emotions, involved in the customer and employee experience within the hospitality and tourism field. 


\section{Tourist experience: The catalyst role of tourism in comforting melancholy, or not}

\section{ABSTRACT}

Although it cannot be interpreted as severe depression, melancholy has disquieted individuals and societies for millennia. This study explores the extent to which tourism can move beyond the formation of enjoyable experiences and become a source of comfort for melancholy. The present study reveals that tourism does not act as a panacea for melancholy. Nonetheless, it may substantially relieve the symptoms through a concurrent amalgam of pleasure and activity factors, distractions, and the seclusion choices it offers. The eagerness associated with an imminent leisure trip and the strength to fight challenges in the personal and social domains following a reviving travel experience are also imperative comforting dynamics. A relevant research agenda is proposed, and the managerial implications for how the tourism industry can secure comforting experiences are discussed.

Keywords: melancholy; depression; tourist experience; leisure; happiness

\section{Highlights}

- Explores causes and paradigms of melancholy.

- Considers the extent of which tourism comforts melancholy.

- Conceptualizes the tourism and melancholy nexus.

\section{Introduction}

The last two decades have seen an impressive number of studies dedicated to the relationship of tourism with positive psychology, well-being, and quality of life (Smith \& Diekmann, 2017; Ryan, 2015; Pyke et al., 2016; Kim et al., 2015). A parallel stem of tourism research has examined the association of tourism with life satisfaction and happiness (Chen \& Li, 2018; Chen et al., 2016; McCabe \& Johnson, 2013; Bimonte \& Faralla, 2012). The positive effects on individuals of traveling and tourism experiences have not gone unnoticed. Tourist experiences have been found to have a positive effect on a variety of life domains (Uysal et al., 2016), while the quest for meditative experiences has been seen to contribute to a sense of personal wellness (Jiang et al., 2018). Nevertheless, Kroesen and Handy (2014) suggested that holiday trips are powerless to raise happiness durably in the long term, and the chronic subjective well-being of tourists was found not to change after a vacation (Chen et al., 2013). 
Despite some useful findings, the vast majority of studies related to tourist activity and to the broader topics of positive psychology and well-being have focused mainly on specific forms of tourism, niche segments, or tourists from specific cultural backgrounds (Li \& Chan, 2017; Moal-Ulvoas, 2017; Kim et al., 2015; Morgan et al., 2015; Chen et al., 2013). Other studies, more specific to the nexus of medical conditions and tourism, have delivered communications and notes with some very useful outcomes (Levi et al., 2019; Filep \& Bereded-Samuel, 2012). Yet, due to their word limit, these studies are deprived from the possibility of allowing in-depth elucidations of the tourism and depression nexus. In fact, there has been little evidence of how tourism affects individuals who are subject to particular conditions such as melancholy, that is defined as "an intense feeling of sadness which lasts for a long time and which strongly affects your behavior and attitudes" (Collins Dictionary, 2019). Although tourism research has channeled its focus toward the positive psychological effects of tourism activity, it has rather surprisingly overlooked the possibility of facilitating the comprehension and comforting of melancholy, which affects people and societies. Though it cannot be interpreted as severe depression (refer to Ohmae, 2012), its debilitating effects include isolation, prolonged sadness, sorrow, fear, and feelings of uselessness (Ioannidou, 2005; Radden, 2002; Lepenies et al., 1992). The aim of this study is to fill this gap in the literature, by exploring whether travel and tourism activity acts as a remedy for people who have experienced a melancholic phase. By doing so the present study, firstly acts upon calls for further research to appreciate the nexus of tourism and depression. For instance, Levi et al. (2019) argued that the very understanding of the nexus of tourism with depression, could yield tourism activities to address tourists with depression. Secondly, it delivers further insights to what has been labeled as a disarming (Trigg, 2009) and rather ambivalent concept (Bowring, 2016). Thirdly, it delivers a fresh perspective from a discipline long heralded as a contributor to the well-being of people and societies. It is expected that the findings will help the tourism industry to secure comforting crescendos towards tourists who may go through a melancholic phase, hence contribute to their destination experience and their overall well-being. The benefits of the study may extent from an individual to societal level. Securing comforting experiences and positive states for tourists may increase the possibility of tourists transmitting their positive states to others, such as family and friends upon their return. Besides, it is wellevidenced that humans transmit their emotional states, such as happiness, to others (Goot et al., 2015; Semin \& de Groot, 2013; Semin, 2007). 
The remaining of the paper is structured as follows: Firstly, a comprehensive review of melancholy literature is provided, followed by a justification of the method used to address the main aim of the study. This paper locates the construct of melancholy within a psychodynamic theoretical context (Borden, 2009), enabling readers to understand its idiosyncrasies and effects, as well as informing the need for further research on the topic. Psychodynamics have been used to examine different phenomena, such as the case of evil (Stone, 2016) anti-bullying (Schwartz, 2016), anti-Semitism (Ostow, 1996) and social networking (Balick, 2018). Though psychodynamics are used in the case of psychotherapy (Johansson, 2019; Gabbard, 2017; Driessen et al., 2015), in a broadest sense, psychodynamic psychology emphasizes psychological forces that underlie human behavior and emotions and how they might relate to the experience of people. Such approach takes into consideration other disciplines, such as medical, social and spiritual, to allow comprehensive results to be obtained. "It [psychodynamic] cannot very well be limited to any one discipline... Only so can fully comprehensive research be maintained" (Guntrip, 1995, p.18). On one hand, this approach involved the search for deeper understandings of melancholy, based on a thorough review of different perspectives of the notion, and emergent empirical literature on its interpretations (Henry et al., 1994). On the other hand, according to the psychodynamic approach, it sought to identify how human functioning as based on the interaction of drives and forces (McLeod, 2017), pursued leisure traveling as a comforting means for melancholy, and how this behavior (of traveling), affected their emotional state. The presentation and discussion of findings is followed by a conclusion in which a diagrammatic approach to the nexus of melancholy and tourism is presented as a guide to future research. The final section discusses certain practical managerial implications before proposing a relevant research agenda.

\section{Literature review}

\subsection{The Hippocratic theory and the melancholy-depression nexus}

The word "melancholia" or "melancholy" "derives from melaina kholé, which means black bile or choler" (Burton, 1857, p. 108). This derives from the belief that an excess of this liquid in the body is the cause of depression (Ioannidou, 2005). According to the theory of Hippocrates, a person is not an isolated system in the cosmos but is directly related to their environment. Hence, any changes in the conditions of the cosmic events in which a person is placed results in (sometimes unfavorable) consequences. As Hippocrates argued, a person is influenced not only by the environment but also by their constitution, the characteristics that 
make a person unique and a distinct entity within the cosmic event. Hippocrates' conception influenced medicine for centuries and is also reflected in modern endocrinology. The wellknown doctor and philosopher argued that the human body consists of four "juices" (also known as bodily fluids, chymoi, or humors), namely "blood" (haima), "phlegm" (phlegma), "yellow bile" (kitrini chole), and "black bile" (melaina chole). The role of these liquids is crucial for the human body, as they maintain the harmony of the body while shaping each person's character (for Hippocrates' theory of juices, see Kalahanis, 2013). According to ancient philosophers, "melancholia" caused black thoughts; hence, although the symptoms of melancholic people differed according to the individual, they could include sadness for a prolonged period, phobias, dysthymia, misanthropy, isolation, and mania (Ioannidou, 2005, pp. 36-38).

\subsection{Philosophical and spiritual perspectives of melancholy}

In medieval philosophy, each person was thought to be dominated by one of the abovementioned humors, such as "melancholy," which was associated with black gall. Dürer's engraving Melencholia I (1514), which shows a darkened face and a cheek resting on the hand, is an allegorical composition alluding to blackness of mood (Metropolitan Museum of Art, 2018). During the seventeenth and eighteenth centuries, melancholia gradually became "restricted to a disease" (Blazer, 2005, p. 42). Of note is the fact that Eysenck's theory of personality (Eysenck \& Eysenck, 1958) was based on four quadrants: phlegmatic, sanguine, choleric, and melancholic, the last of these being emotionally unstable and introverted, with characteristics such as moodiness, pessimism, unsociableness, and quietness. Although the construct of melancholy has been subject to various interpretations (Trigg, 2009), its link with the current terminology of depression is noteworthy, and it is extremely difficult to separate the two. For instance, melancholy seems to possess the same deleterious properties as denoted by the contemporary use of the Greek term stenohoria, which may be interpreted as a rather incessant condition of sadness. From a spiritual perspective, depression may be a sign of spiritual weakness (Rogers, 2002) while stenohoria is regarded as a "disease of the heart"; Despite the satisfaction of materialistic demands, a person is driven to a one-dimensional life in which spiritual values cease to exist. When the deeper pursuits of a person are neglected, their psychological health is shaken. Consequently, a person lives what is essentially a life without grace, a situation that stems from inner emptiness and exuberant anxiety (Athanasiades, 2017). 


\subsection{A medical perspective: The nexus of melancholy and depression}

Even though the term "melancholia" has not disappeared completely from the terminology of psychopathology, the term "depression" has tended to replace it (Ioannidou, 2005). Indeed, reported symptoms of depression would seem to ancient ears to coincide with those of melancholia.

People who say "I'm depressed" often mean "I'm discouraged. Life isn't going well for me right now" ... Sadness is characteristic of depression, but lack of happiness is even more characteristic. (Kalat, 2011, p. 590)

Several studies have linked the notion of melancholy with depression, as in the case of melancholic depression (Weinberg, 2016; Khan et al., 2006; Winograd-Gurvich et al., 2006; Hill \& Gorzalka, 2005), melancholic major depression (Rothermundt et al., 2001), and pharmacotherapy for major depression with melancholic features (Perry, 1996). Nonetheless, certain researchers have agreed that "melancholia" in ancient times and during the seventeenth and eighteenth centuries seems to have meant what "depression" means today (Blazer, 2005; Ioannidou, 2005). All the same, depression is characterized by different types. These are mainly based on the situation of the person under depression. For example, major depression, dysthymia, postpartum depression (sadness after having a baby), Seasonal Affective Disorder (SAD), Losing touch with reality (called Psychotic depression), Bipolar disorder (from high to low, and high again), premenstrual dysphoric disorder, and situational depression (that is, when life gets you down). Furthermore, there is also DSM-5 also known as Diagnostic and Statistical Manual of Mental Disorders, which includes symptoms of even more types of depression. Even so, melancholy and depression may not necessarily bear the same meaning, since the American Psychiatric Association recognizes melancholy as a subtype of Major Depressive Disorder (MDD). Post \& Warden (2018), make reference to depression with melancholic features, such as anhedonia and sadness. Whatever their other associations, Radden 2002 (p.19) postulates that melancholy and depression are today viewed as 'states suffered'. Even so, alike the reasoning offered by Ohmae (2012), we postulate that melancholy may not be interpreted as severe depression (or, MDD) with a combination of symptoms such as, persistent negative thoughts, lack of motivation and continuous bad mood, yet not as severe as, excessive thoughts of death or suicide.

\subsection{Causes, symptoms, and treatment of depression and melancholy}


Freud considered melancholia as a process taking place in the unconscious mind of a person who grieves for a loss that he is unable to fully identify or comprehend (Freud, 1917). Likewise, Radden (2002, p. 19) considered melancholy as a "not-sought condition, beyond voluntary control." Although no gene is specific to depression, genetic factors influence people's likelihood of depression (Kalat, 2011). Despite this, a plethora of studies has revealed various causes of depression, such as the family environment. For instance, a major predictor of the onset of depression is having a depressed parent (Loechner et al., 2017). Causes of depression reported by participants of a study by Park et al. (2018) included socioenvironmental, religious, health-related, and lifestyle factors. Moreover, work environment and working conditions have been found to affect people negatively; Griffiths et al. (2018) reported that the mental and physical demands of working in care homes led to stress-related illnesses, such as depression. Occupational stress (for example, within the educational environment) was also found to predispose to depression (Desouky \& Allam, 2017). Furthermore, virus exposure, such as the exposure of adults to herpes simplex virus type 2, was found to be associated with depression (Gale et al., 2018). Depression is among the most frequent neuropsychiatric complications of stroke (Ayasrah et al., 2017). In addition, certain addictive behavior may cause depression; from the data of around 5800 respondents to the Health Survey for England, it was found that drinking alcohol promoted depression (Churchill \& Farell, 2017). Another study found that the high prevalence of gambling in the UK was associated with emotional and mental health costs (Churchill \& Farell, 2018). Under certain biological and life circumstances, gender variations exist, including perinatal and postnatal depression for women (Zhao et al., 2018). Similarly, Mulhall et al. (2018) found that the likelihood of symptoms of depression increased during the female perimenopause.

The socio-economic and physical environment also plays its part. It is no coincidence that severe economic turndowns are referred to as "depressions," including the "Great Depression" in the USA during the 1930s (Bernstein \& Bernstein, 1989). This economic depression affected the world (Rothermund, 2002), and its social impacts have been documented; for example, suicide mortality increased during this period (Granados \& Roux, 2009). A significant association between economic hardship and major depression was recorded during the severe financial crisis that affected Greece in 2008-2011 (Economou, 2013). Approximately one in ten people living in New York City in 2001 became depressed within six months following the dreadful terrorist attack (Person et al., 2006). Although weather conditions and depression were not found to be associated with depression (Huibers 
et al., 2010), Sack et al. (1990) reported that patients with winter depression may benefit from bright light. Likewise, Molin et al. (1996) reported lack of light as a contributing factor for the development of depression in winter. In Seasonal Affective Disorder, a variant form of depression, people become depressed during a particular season of the year. This can be seen in the case of explorers in specific locations with long winters, such as Antarctica (Palinkas, 2003).

Depression is common from adolescence through old age, yet few people remain permanently depressed (Kalat, 2011). Abraham Lincoln experienced a melancholic phase in which he spoke openly of suicide, after he suffered a major depressive episode following the death of Ann Rutledge, for whom he had strong feelings (Shenk, 1989). Researchers recorded the expressions of depressed people who were shown different pictures, and they showed almost no response to the pleasant pictures (Sloan et al., 2001). Several studies in recent decades provided findings that support the remarkable relationship between variation in sleep and abnormalities in depression (Tsuno et al., 2005; Healy \& Williams, 1988). In fact, depression has a combination of diverse symptoms, including anhedonia, lack of motivation, low energy, low self-esteem, and discomfort with no clear cause (Yang et al., 2018). Symptoms may also include persistent negative thoughts, continuous bad mood, feelings of despair and isolation, lack of interest and attention, sleep disturbance, crises of anxiety and self-confidence, changes in appetite, impatience or irritation, loss of libido, self-destructive behavior, and suicidal thoughts (Puri \& Boyd, 2005). Of note are certain somatic symptoms that may be linked to the aforementioned Hippocratic theory:

A 30-year-old unmarried female worker; very pale, whining voice, seems depressed ... When we saw the patient the second time, she displayed only three symptoms, all of which corresponded with the spleen. The focus of therapy shifted to the spleen-melancholy. (Ots, 1990, pp. 35-36)

Symptoms of depression have been measured using different techniques and on various scales, such as the Goldberg Depression Scale (Mulhall et al., 2018), the Center for Epidemiologic Studies Depression Scale, and the Geriatric Depression Scale (Sarfo et al., 2017). Symptoms of depression differ significantly between individuals, which makes its diagnosis a difficult task. In particular, the manner in which each person experiences depression varies according to symptoms, degree, and duration. However, the underlying feeling of continuous desperation and disappointment is the same (Puri \& Boyd, 2005). When a person 
experiences little interest, motivation, ability to concentrate, or pleasure for most of each day for at least two weeks, they are said to suffer from "major depression" (Kalat, 2011, p. 590). Treatments vary, and they may include antidepressant drugs, psychotherapy, exposure to light, and an active lifestyle (through the inclusion of exercise in the patient's routine). Exercise has shown promise as an effective treatment for depression (Gujral et al., 2017). Psychotherapy is particularly helpful, as has been shown in cases of interpersonal therapy, which focuses on helping people cope with problems such as unemployment or divorce (Hollon et al., 2002). The findings of Kozhyna et al. (2017) supported the use of art therapy in the treatment of patients with melancholy.

\subsection{The impacts of tourism on the wellbeing and psychology of people}

Tourism and leisure activities may have a positive impact on the psychology and wellbeing of people. In more detail, emotions play an important part in tourism and the tourist experience (Gibson \& Yiannakis, 2002). This is because tourists and tourism providers are required to face, or address both positive and negative emotions, such as happiness and sadness (Coleman and Iso-Ahola, 1993; Bigne \& Andreu, 2004). Tourists may engage in leisure and tourism activities in order to experience particular emotions, such as joy and happiness, improve their overall wellbeing, or in order address certain personal conditions, such as depression. It has been argued that tourism contributes to a tourist's wellbeing (McCabe \& Johnson, 2013) while the nexus of tourism with positive psychology and/or happiness, is a well-explored topic (Chen \& Li, 2018; Filep, 2012). Various leisure activities generate shortterm benefits, such positive mood, and long-term effects, such as enhancing happiness and mental health (Lu, 2011; Lu \& Hu, 2005; Argyle, 1996). For instance, in the study of Lu (2011), older people who were getting together in key locations in order to chat and drink tea, were found to satisfy their social needs and were correlated with lower levels of depressive symptoms. On the contrary, low levels of certain activities (such as, physical activity), may be associated with a greater risk of depression (Mikkelsen et al., 2010). The pursuit of happiness acts as a pull stimulus for tourists. A "happy" country attracts tourists while there is a positive feeling associated with visiting a happy country. This is because the country's happiness is conveyed to tourists while spending their holidays there (Yong \& Xiang, 2018; Gholipour et al, 2016). Also, people who face symptoms of depression try to cope with it through leisure travelling (Galit et al., 2012). The study of Fullagar (2008, p.47) found that "by asserting their sense of entitlement to leisure, women embodied experiences that allowed them to feel their way through recovery..." Dupuis and Smale (1995) concluded that specific leisure activities 
(such as, those that provide opportunities for freedom of choice, self-expression, and creativity) bring about higher psychological wellbeing and lower depression among older adults. Nonetheless, depression may discourage people to get engaged with leisure activities (Galit et al., 2012; Coleman \& Iso-Ahola, 1993). Particularly, Nimrod et al. (2017) report that the more depressed people feel, the less they are able to participate in leisure activities, and the less involved they are, the more depressed they become. Even so, while on holidays, people may use certain emotional regulation strategies to address negative emotions and states. Recent studies examined emotion regulation as an intervention for those tourists who wish to maximise their travel experience (Gao \& Kertetter, 2018). In fact, tourists use a number of emotion regulation techniques (such as, intrapersonal and interpersonal) in order to alter their state of mood (from unhappy to happy), during their holidays (Gao et al., 2017; Nawijn et al., 2013).

Despite the above, therapy can be enforced through the use of antidepressant medications, such as tricyclics, monoamine oxidase inhibitors, and serotonin reuptake inhibitors (Kalat, 2011). However, Puri and Boyd (2005) urged people to think carefully prior before commencing intake of antidepressants, given that these medications may have numerous side effects. Furthermore, while they may address a current episode of depression, they do not protect against future crises. The treatment of depression has therefore remained a challenge (Ampong, 2018), and according to Park et al. (2018), public beliefs about psychiatric disorders, including depression, are important for understanding help-seeking behaviors. All the same, Levi et al. (2019), call for further research to appreciate the nexus of tourism and depression.

\section{Methodology}

\subsection{Justification of study methods}

The research was carried out within a three-month period in 2018 and targeted tourists. These were purposely targeted in their natural setting (that is, while holidaying) to facilitate the process of identifying information-rich cases (Palinkas et al., 2015; Patton, 2014; Suri, 2011). People on vacation are at ease, which assists with the extraction of confidential personal emotional information (Christou, 2018). Furthermore, given the exploratory and rather phenomenological nature of the study, a qualitative approach was deemed appropriate alike analogous studies (e.g. Christou \& Sharpley, 2019), since it contributes to in-depth understanding of personal phenomena (Christou \& Farmaki, 2018). Tourists were approached by two experienced researchers who ensured the anonymity of interviewees and who were informed of ethical issues involved. More specifically, tourists were found in their 'natural 
setting' (that is, while holidaying), in this case, in the country of Cyprus. This particular destination has been used for analogous investigations in the past, since it offers easy access to information derived from tourists of different origins and interests and heterogeneous characteristics. The specific destination provided an appropriate context, since it is well known as a holiday destination for tourists, mainly European, from a variety of cultural, age, and occupational backgrounds. Therefore, it was anticipated that the views of different people would be included in the study. The fact that that the majority of tourists visit the country for leisure purposes made it easy for researchers to approach them in their natural setting (for example, in town squares) and gave more time to chat with them. The researchers recruited their participants based on purposeful sampling, with sampling criteria including those who have experienced melancholy and travelled during that period. As Patton (2007) stressed, qualitative inquiry typically focuses in depth on relatively small samples that are selected purposefully. Certain people were not willing to participate; others, although they indicated that they had experienced a melancholic phase at some point in their lives, had not — purposely or coincidentally - gone on vacation during that period. Some people indicated that they had experienced a melancholic phase but that they had not been willing or able to go on vacation (for instance, because they were unable to find the psychological and physical strength to do so). These were not included in the sample, because the main aim of the study was to understand the effects of tourist activity on people who were experiencing a melancholic phase.

\subsection{Guiding questions}

Questions guiding the study were structured according to its main aim. Prior to the interviews with tourists, the researchers made contact with two professional psychologists and three psychiatrists for advice on how to shape the questions related to melancholy and its symptoms. Informants were asked whether at a specific time in their lives they had experienced a phase (of around two weeks) in which they felt a combination of symptoms (not necessarily all of them) such as feeling drained, lack of motivation, low energy, persistent negative thoughts, continuous bad mood, feelings of despair and isolation, lack of interest, inability to perform daily activities as usual or as before, feeling unhappy or miserable, crying, feeling angry, and sleep disturbance. The general questions that guided this study were the following:

- What do you believe caused this state (of melancholy)? Did you seek any professional help? Did you take any medication? 
- Did you go on vacation during that period? Why? Where? With whom and for how long? Where precisely did you stay (in a resort, at a hotel, with friends)? (this question, based on psychodynamic forces, sought to identify which precise drives and forces led participants to a particular behavior, and how these motives shaped their travel choice).

- Did the vacation ease the melancholic symptoms? Why, or why not?

- If the vacation eased the symptoms, which precise actions or experiences at the destination made you feel better? (this question aimed to make informants think deeply of any actions that might have eased their melancholic state),

- How long did this positive state last for? In other words, did it continue after the vacation experience?

As noted above, tourists were first approached in their natural setting, and those who agreed to participate in the study were interviewed by two experienced researchers, either at that time or later at a pre-arranged location (for example, in a hotel reception). A complete list of the eventual participants in the study (with relevant information) is provided in Table 1.

$<$ Insert about here Table 1: Profile of informants $>$

\subsection{Interview information, saturation and analysis of findings}

Each interview lasted around half an hour, guided by the questions mentioned in the previous sub-section. Researchers took notes before, during, and after the interviews in order to capture important verbal and non-verbal information (Christou et al., 2018). The study came to an end when new information was found to be reinforcing information already collected (Suri, 2011); hence, a total of 60 informal interviews were retained and included in the study. In more detail, at this point saturation of findings was achieved given that newly collected information was basically re-enforcing what had already been collected from other participants (Mariampolski, 2006), alike studies that have used similar qualitative approaches (e.g. Christou et al., 2019). Saturation was operationalized in a way that it was consistent with the aforediscussed research questions, while not risking saturation losing its coherence and potency (Saunders et al., 2018) while seeing 'similar instances over and over again' and becoming empirically confident that the findings were saturated (Glaser \& Strauss, 1967, p.61). Interviews were conducted in English and were transcribed by two professionals. The information analysis involved axial coding, a commonly used method during qualitative data analysis that involves the breaking down of core themes (Blair, 2015). A coding paradigm was 
followed that included categories related to: a) the phenomenon under study, b) the conditions related to the phenomenon, c) the actions strategies related to the phenomenon, and d) the consequences of the actions related to the phenomenon (Strauss \& Gorbin, 1998). The process involved the identification of themes and the assessment of their understanding in relation to the literature (Di Domenico \& Lynch, 2007). Emerging topics were grouped into interrelated categories according to key themes identified through the examination of transcripts and notes from the interviews. That is, blocks of verbatim transcript were organized on the basis of the previous questions, cross-referenced (by two researchers), and reorganized following the identification of thematic categories that emerged from the fieldwork. The categories were organised around the central explanatory concept (that is, melancholy) while the process assisted in the formation of more precise and complete explanations of the phenomenon, hence allowing the theory to emerge (Strauss \& Corbin, 1998). An axial coding analysis diagram is provided below that illustrates clearly the context of the study (phenomenon under study: Melancholy and tourism), the conditions related to the phenomenon (such as, personal conditions causing melancholy), actions (travel and tourism actions), and consequences of the actions related to the phenomenon.

$<$ Insert about here figure $1>$

Findings are reported through tourists' thick descriptions, confirming validity in qualitative inquiry (Creswell \& Miller, 2000), and are presented in a format comparable to that of analogous qualitative studies (e.g. Sharpley \& Jepson, 2011).

\section{Results}

\subsection{Causes of melancholy}

As mentioned above, the informants who were retained in the study are those who indicated that, on at least one occasion in their lives, they had experienced a "melancholic" phase. These participants communicated various causes of their melancholy, such as daily difficulties, medical issues, and occupational reasons, adding to the discussion of what causes melancholy and depression (Park et al., 2018; Loechner et al., 2017). For instance, one participant gave this account:

My day-to-day life consists of working full-time, with two daughters aged five and seven ... both are in school, with extra-curricular activities ... as well as taking care of the house, with elderly parents. My life at the moment 
is being constantly on the run, rushing from here to there, trying to meet these obligations ... My husband's day is identical to mine. Usually, three-quarters of the way through the year, I start to feel very run down and very tired, physically, mentally, and psychologically ... We plan a holiday for the January holidays and that keeps us going till the end of the year. (Mary, 4049, Australia)

However, it should be noted that there were cases in which informants made reference to various triggers of melancholy and not solely one factor. For instance,

I guess those feelings [referring to negative emotions] were triggered by excessive stress on multiple levels ... such as educational, financial, personal reasons, and my work ... I did not feel motivated to continue struggling with the balance between all these issues. (Viktoria, 20-29, Bulgaria)

Causes of melancholy, as mentioned by the interviewees, are grouped and presented in detail, in Table 2, which includes representative quotes of informants.

$<$ Insert about here Table 2: Causes and paradigms of melancholy>

\subsection{Traveling and tourism experiences as a remedy?: Specific comforting actions and experiences}

A few interviewees mentioned that they had sought professional help, referring to psychologists and/or psychiatrists, and yet only one of them revealed that they took medication. This is despite evidence suggesting that the use of antidepressant medications is relatively common (Kalat, 2011). The vast majority of respondents either did not give a direct reply or indicated that they did not think that they could benefit from professional help. Instead, they received comfort from others and engaged in particular activities (for instance, walking in the countryside). A small number pointed that they did not have the courage to seek help. The following quotes are representative:

I did seek help from the university psychology counselors ... I was seeing them for about two months, but they did not recommend any medication. (Viktoria, 20-29, Bulgaria)

My "medication" was the university and my hobbies ... painting, stitching, and reading ... also, walks in the countryside. (Anastasia, 20-29, Russia) 
I did not have the courage to seek help, but I'm planning to, one of these days ... soon ... (Matthew, 60-69, UK)

Of particular note is the fact that the majority of the interviewees stated that they purposely arranged to go on vacation during the phase when they were experiencing melancholic symptoms. This probably reflects personal perceptions that such an experience would ease melancholic symptoms. There is a considerable amount of scientific evidence to support the positive psychological effects of tourism activity (for example, happiness and eudaimonic experience studies).

Most informants chose to go on vacation with family, partners, or friends. The chosen location varied from islands and beach destinations to countryside settings and other European and Asian destinations; no particular destinations were found to be associated with clusters. The vast majority of respondents chose leisure holidays of one to two weeks, with the average length of stay being eight days, in international (rather than domestic) destinations. The majority of them, chose to go to island destinations, such as in Europe (i.e. the Greek islands) and Asia (Fiji Islands). Interviewees referred to staying in various types of paid-for and nonpaid-for accommodation (for instance, hotels and being hosted by relatives). However, several responses indicated vacations in calming, luxurious, and comfortable establishments, such as "a beautiful hotel apartment," "a five-star luxury resort," "a luxurious hotel on an all-inclusive package," and "a villa with a swimming pool, next to the beach." Certain travel characteristics of informants, are provided in table 3.

\section{<Insert about here Table 3: Travel characteristics of informants $>$}

A frequent comment of informants, was that "it [the trip] helped a lot."

Absolutely! ... Getting away from routine, change of scenery. Being surrounded by new people ... (Sophie, 40-49, UK)

Definitely [referring to a city break], it helped me to feel happiness, freedom and see new perspectives ... It helped me get rid of the feeling of emptiness by concentrating on new emotions, new pleasant feelings, and learning from the different culture. (Anastasia, 20-29, Russia)

I believe the quality time spent on a holiday gives relief by lifting your spirits, relaxing your body and mind, recharges your batteries to face reality and get on with your daily life, work, and routine. (Chrystal, 50-59 UK) 
In certain studies, weather conditions and depression were found not to be associated (Huibers et al., 2010). Nevertheless, in several cases, interviewees made reference to the remedying effects of "sunshine," "warm climate," and "good weather conditions". The finding that tourism activity "eased" melancholic symptoms came as no surprise. However, this study revealed precisely which activities and factors are capable of comforting the melancholic traveler. Informants referred to particular elements and experiences, or a combination of these, which seemed to possess a soothing-melancholic dynamic. Each of these elements and experiences appeared to contribute to the comfort of people with melancholic symptoms. On the basis of the findings of this study, they can be grouped into four general themes. These are presented in Table 4.

\section{<Insert about here Table 4: Remedying (tourism) factors towards melancholic symptoms>}

\subsection{The duration of comforting feelings}

On the basis of the interviewees' replies to the general question of how long the comforting feeling lasted, four clusters of people were identified. The first cluster stressed that melancholic symptoms eased only while they were having the holiday experience.

It did not last after the holiday. In fact, it lasted only a few days while I was on holiday. I was already overthinking, and when the first couple of weeks passed I also got homesick, which added to the negative state. (George, 20-29, UK)

Well, the holiday helps ... up until you get back to your routine and get back to work ... Just thinking about it demoralizes you. But I need to add that this wasn't the case when working in the UK, as the environment I was working in was very professional and positive [note: the interviewee now resides abroad]. I think external factors also have an impact on how long the "holidaymoon" lasts! (Sophie, 40-49, UK)

The second cluster said that the comforting feeling continued on their return to their home setting but soon vanished; this was attributed to various factors, mainly the return to the "routine" and "everyday problems."

The positive state usually starts to fade away pretty soon after, as you are thrown back into your daily routine ... But this is life. Throughout the year, 
we normally spend some time away, with a few nights here and there, and this usually helps us to keep us on track. (Mary, 40-49, Australia)

The third cluster pointed out that the comforting feeling lasted from a few weeks to a couple of months. This adds to the discussion in previous studies (e.g., Kroesen \& Handy, 2014), which found that holiday trips are unable to raise levels of happiness in the long term:

It lasted for a few weeks after I returned. Afterwards, I started feeling bad, and I had to take medication for a year due to depression. But those holidays changed the way I was looking at things ... It made me feel positive once again and enjoy the simple things in my life, such as nice surroundings and happy faces. (Nour, 40-49, Lebanon)

Another cluster was identified: those who indicated that the positive feeling lasted for a long time as a result of memory retrieval. These interviewees cited the general and strong impact that their trip had on their lives, the strength that they gained through their trip experience (that is, the strength to overcome difficulties), and a new way of viewing life:

I was strong throughout my journey with cancer, and I believe those holidays helped me find a new purpose in life. I wanted to stay strong and healthy so that I could go again. And I managed to survive, and now, after 15 years, I am strong and happy, and I would like to go back to France for holidays. (Kyriaki, 60-69, Cyprus)

\section{Discussion and conclusions}

Of note is the fact that interviewees from different age groups made reference to melancholic symptoms, thereby corroborating the theory that melancholy is common for people of all ages (Kalat, 2011). An important outcome of this study is the fact that certain causes of melancholy were found to varied and to be linked with age. For example, young interviewees (20-29 years old) referred to stress, particularly in relation to education, while older informants (over 60 years old) referred to thoughts related to death and mortality. Previous studies have revealed that occupational stress predisposes to depression (Desouky \& Allam, 2017), and a large proportion of respondents (one-third) made reference to work-related causes, including stress caused by the demands of work, pressures from the employing organization, and overwork. Based on responses provided by informants, causes of melancholy may be grouped into four main categories according to the replies given by informants: 
personal, organizational, relationship, and environmental causes. It should be noted that each of these domains may interfere with and affect the others. For instance, stress caused by the employing organization may affect relationships with others (such as colleagues and partners). Furthermore, a general economic crisis can cause financial difficulties, which may lead to additional worries in people's personal lives. Of particular note are the changes throughout the centuries in the causes of melancholy; informants in the current study made reference to "technology," which may affect us in a negative manner (for instance, by causing further stress in our lives). This is another interesting outcome of the present study, worthy of additional examination by future researchers.

In previous studies (e.g., Sloan et al., 2001), researchers recorded the expressions of depressed people, who showed almost no response to pleasant pictures shown to them. Though it has been argued that depression may discourage people to get engaged with leisure activities (Galit et al., 2012; Coleman \& Iso-Ahola, 1993), in the present study, almost all interviewees revealed that their travel experience eased their melancholic symptoms. This was the result of the creation of pleasant experiences, relaxed conditions, distractions from certain negative emotions, and the formation of positive emotions. Although certain of the abovementioned activities may be undertaken while people are in their home settings, tourism provides opportunities for a combination of these. However, as afore-discussed, melancholy may not be interpreted as severe depression (Ohmae, 2012). Hence, it may be argued that someone who is diagnosed by a professional with MDD may not necessarily experience positive psychological states, regarding his/her travel experience. For instance, the post-trip reactions of patients who were suffering from MDD, were found to varied in the study of Levi et al. (2019). Previous studies found that tourism contributes to the wellbeing of tourists (McCabe \& Johnson, 2013) and leisure activities, such as those that provide opportunities for freedom of choice and creativity, lower depression (Dupuis \& Smale, 1995). The significance of physical activity is highlighted in this study- as in previous studies (Mikkelsen et al., 2010). Certain leisure activities, such as getting together with other people, chatting, socially bonding with others, and drinking tea were found to be correlated with lower levels of depressive symptoms ( $\mathrm{Lu}$, 2011). Also, while on holidays people may use emotion regulation to maximize their experience and alter their state of mood (Gao \& Kertetter, 2018; Gao et al., 2017; Nawijn et al., 2013). Furthermore, this study revealed that people on vacation may have more time to socialize with certain people who are important to them. If they do not have to worry about work and household tasks, they may have more free time to engage in favorable activities. 
Furthermore, it seems that tourism and melancholy have certain dynamics, each affecting the other: tourist activity has an impact on melancholy, and melancholy affects individuals during their travel experience. This interplay of dynamics between tourism and melancholy is illustrated in Figure 2.

\section{$<$ Insert about here Figure 2: The interplay of tourism and melancholy>}

The aim of the present study was to explore whether tourism acts as a remedy for people who have experienced a melancholic phase. Besides as Ioannidou (2005) noted, melancholy remains an illness that affects an enormous number of people, who are trapped in the net of depression it causes. The outcomes of this study enabled us to construct a diagram detailing the tourism-melancholy nexus. This diagram contributes to the theoretical discussion of the tourism and melancholy nexus, and may be used by future researchers to further advance our understanding of tourism activity on the wellbeing of people. Despite the comforting effects of touristic activity on individuals, melancholy impacted on all phases of the travel experience. For instance, individuals communicated the "fear," while on vacation, of returning back from a holiday to their problems.

Probably the most important outcome of this study is the fact that tourism does not act as a panacea to melancholy. This is because negative and melancholic thoughts accompany the individual, prior, during and after the trip. The significance of this outcome rests on the fact that individuals may wrongfully assume that a leisure trip may act as a complete and holistic antidote to the state of melancholy they are in. Based on the long heralded affirmative effects of tourism on the well-being, happiness levels and overall positive psychology of people (Chen \& Li, 2018; McCabe \& Johnson, 2013; Filep, 2012; Lu, 2011), people may pursue the arguably wrong path of traveling for healing their psychological states. This, instead of alternatively try to deal with their problems first, or seek for assistance and psychological support by professionals. However, based on the outcomes of this study, it appears that there are certain melancholy-remedying effects offered by tourism that are necessarily restricted to the phase in which people are on vacation. Responses revealed that the "hope" and "anticipation" of a future holiday gave interviewees the strength to overcome problems that may have caused them to become melancholic (see Figure 3). However, this outcome could not have been the case, had the informants been diagnosed with MDD (alike the case of participants in the study of Levi et al., 2019). In the present study, a leisure trip also prepared informants to fight against the causes of melancholy; for example, it equipped them to deal with workplace problems in a more 
positive manner and to be more optimistic when dealing with challenges. Furthermore, depending on the trip experience, people may have returned with "fond memories," novel experiences, and perhaps new perspectives on life. Such was the case of Kyriaki (60-69, Cyprus, retired), whose holidays helped her to find a new purpose in life and deal with cancer. Finally, the holiday experience seems to have "recharged" peoples' batteries to deal with daily challenges, such as those related to the daily life, work and routine.

<Insert about here Figure 3: The tourism-melancholy nexus>

\section{Limitations and future studies}

A number of limitations of this study ought to be acknowledged. First, this study was not able to differentiate the extent to which each individual was experiencing melancholy; for instance, the condition of a particular interviewee might have been more severe than that of others. Second, despite the informants being given a list of melancholic symptoms, they themselves determined whether they had experienced an episode of melancholy. It was almost impossible in terms of time and costs to have psychiatrists examining each of these cases, and the interviewees' self-diagnoses may be subject to multiple interpretations. Third, because of the nature of the study, there is a possibility that individuals did not disclose certain important information. For instance, the fact that only a few indicated that they had sought professional help, and that only one had taken medication, raises the issue of whether others were not comfortable sharing such information with the interviewers. Fourth, informants reported that they purposely went on vacation to ease their melancholic symptoms, but it is possible that their trips combined a number of motivations for travel. Although beyond the scope of the present research, this study does not provide information about people who did not go for holidays during their melancholic phase. As discussed in the theoretical part of this study, the more depressed people feel, the less they are able to participate in leisure activities, and the less involved they are, the more depressed they become (Nimrod et al., 2017). Fifth, the study was not able to pinpoint possible differences between clusters of interviewees. However, it has contributed to the discussion of which specific actions may comfort melancholic symptoms. Of course, this does not imply that tourism activity can replace other therapeutic-professional means of treating melancholy.

The limitations of this study provide opportunities for further research, thus assisting in the creation of a relevant research agenda. In particular, the theoretical conceptual framework of the tourism-melancholy nexus could be used by future academics further to examine the 
relationship between melancholy and possible comforting actions. For example, it would be very interesting to investigate the possibility of extending the remedying effects of touristic activity during the meta-trip phase. Tourism researchers may offer further insights into the comforting effects of tourist activity on melancholic people. Each of the four main pillars of tourism's comforting effects on melancholy (for example, the distraction factor of exploration) presents good prospects for further research. For instance, researchers may explore the role of spiritual activities in comforting people who are experiencing a melancholic phase, since as discussed in the theoretical discussion of this paper, melancholy has a spiritual element attached to it (refer to the previously discussed notion of stenohoria).

\section{Implications}

This study sought to contribute - through the prism of tourism — its share in addressing the debilitating effects of melancholy, which has not ceased to trouble people for millennia. As Blazer (2005) emphasized, we live in an age of melancholy, which has become a hazard to worldwide public health. Most importantly, the study provided insights to melancholy, which although it may not be interpreted as severe depression (Ohmae, 2012), it remains a "state suffered" (Radden, 2002, p.19) by individuals. As a result, this study has yielded a number of managerial implications directed toward destinations, tourism organizations, and entrepreneurs. In more detail, based on the outcome that tourism does not act as a melancholyantidote, destinations and resorts must be extremely careful in the words they choose to include in their promotional campaigns. For example, by stating that their experiences or therapies rejuvenate the spirit and uplift the psychology and state of mind of participants, may potentially lead tourists to perceive that such experiences may expunge their melancholy. A considerable number of resorts globally currently offer spa and healing opportunities to their guests. These, could also consider employing professionals in rejuvenating centers, such as psychologists, with the aim of offering advice to individuals who may suffer from melancholy, or similar states. By doing this, they can enhance the visitor experience with an additional, helpful and meaningful service. The resorts can encourage visitors to visit their professionals as part of a "soothing and comforting" experience that goes beyond somatic relaxation. This offers a fresh perspective of spas which normally contributing instantly to the well-being of their clients, through hedonistic experiences (Voigt et al., 2011). Furthermore, such professionals may provide advice and support to individuals to seek further professional help, upon their return to their home settings. In this way, tourism can play a catalyst role in channeling people who suffer from melancholy (or more severe conditions), towards professionals for psychological 
support. In addition, entrepreneurs could consider investing in resorts that operate as healing sanatoria; that is, leisure, exercise, tranquility, and rejuvenation activities may be combined with support and guidance from professionals. Some may consider the possibility of encouraging "detoxication" from technology (and specifically from the internet), given its effects on people's psychology in terms of stress and pressure. Although the limited time spent at the destination or resort may not be enough to ensure long-term healing, it may nevertheless lead to diagnosis and a recommendation to seek further professional support. Finally, destinations could collaborate with tour operators to promote packages of healing and psychological rejuvenation activities, which could specifically target tourists emerging from a melancholic phase in their lives. These could be promoted as "psycho-somatic rejuvenation" packages, since certain individuals may wish to avoid being linked with labels such as "depressed."

In conclusion, this is one of the very few studies that have attempted to examine from a tourism perspective a socio-psychological phenomenon that has troubled societies and individuals for millennia. We hope that it will be welcomed by tourism researchers as an intriguing basis for analogous future explorations of melancholy and similar conditions.

\section{REFERENCES}

Ampong, D.N. (2018). Depression and Pharmacogenetics. Archives of Psychiatric Nursing, 32 (1), 71-74.

Argyle, M. (1996). The social psychology of leisure. London: Penguin Books.

Athanasiades, G. Archim. (2017). Stenohoria: I astheneia tis kardias, Athens: O Sotir. ISBN: 978-618-5107-33-8.

Ayasrah, S.M., Ahmad, M.M. \& Basheti, I.A. (2017). Post-Stroke Depression in Jordan: Prevalence correlates and predictors. Journal of Stroke and Cerebrovascular Diseases (corrected proof as at 07/02/2018).

Balick, A. (2018). The psychodynamics of social networking. London: Routledge.

Bernstein, M.A. \& Bernstein, M.A. (1989). The Great Depression: delayed recovery and economic change in America, 1929-1939. Cambridge University Press. 
Bigne, E. \& Andreu, L. (2004). Emotions in segmentation: An empirical study. Annals of Tourism Research, 31, 682-696

Bimonte, S. \& Faralla, V. (2012). Tourist types and happiness a comparative study in Maremma, Italy. Annals of Tourism Research, 39 (4), 1929-1950.

Blair, E. (2015). A reflexive exploration of two qualitative data coding techniques. Journal of Methods and Measurement in the Social Sciences, 6(1), 14-29.

Blazer, D.G. (2005). The age of melancholy:" major depression" and its social origins. Taylor \& Francis.

Borden, W. (2009). Contemporary psychodynamic theory and practice. Chicago, IL.: Lyceum Books.

Bowring, J. (2016). A Field Guide to Melancholy, Oldcastle Books, Limited.

Burton, R. (1857). The anatomy of melancholy. JW Moore.

Chen, C.C., Huang, W.J. \& Petrick, J.F. (2016). Holiday recovery experiences, tourism satisfaction and life satisfaction. Tourism Management, 53, 140-147.

Chen, Y., Lehto, X.Y.\& Cai, L. (2013). Vacation and well-being: A study of Chinese tourists. Annals of Tourism Research, 42, 284-310.

Chen, Y. \& Li, X.R. (2018). Does a happy destination bring you happiness? Evidence from Swiss inbound tourism. Tourism Management, 65, 256-266.

Christou, P. (2018). Exploring agape: Tourists on the island of love. Tourism Management, $68,13-22$.

Christou, P. \& Farmaki, A. (2018). Utopia as a reinforcement of tourist experiences. Annals of Tourism Research. https://doi.org/10.1016/j.annals.2018.11.003

Christou, P. \& Sharpley, R. (2019). Philoxenia offered to tourists? A rural tourism perspective. Tourism Management, 72, 39-51. 
Christou, P., Hadjielias, E. \& Farmaki, A. (2019). Reconnaissance of philanthropy. Annals of Tourism Research, 78.

Christou, P., Farmaki, A. \& Evangelou, G. (2018). Nurturing nostalgia?: A response from rural tourism stakeholders. Tourism Management, 69, 42-51.

Churchill, S. A. \& Farrell, L. (2017). Alcohol and depression: Evidence from the 2014 health survey for England. Drug and Alcohol Dependence, 180, 86-92.

Churchill, S.A. \& Farrell, L. (2018). The impact of gambling on depression: New evidence from England and Scotland. Economic Modelling, 68, 475-483.

Coleman, D. and Iso-Ahola, S.E. (1993). Leisure and health: The role of social support and self- determination. Journal of Leisure Research, 25 (2), 111-128

Collins Dictionary. (2019). Definition of 'melancholy'. Available online: https://www.collinsdictionary.com/dictionary/english/melancholy. Accessed: 10/2019.

Creswell, J.W. \& Miller, D.L. (2000). Determining validity in qualitative inquiry. Theory into Practice, 39 (3).

De Groot, J.H., Smeets, M.A., Rowson, M.J., Bulsing, P.J., Blonk, C.G., Wilkinson, J.E. \& Semin, G.R. (2015). A sniff of happiness. Psychological Science, 26(6), 684-700.

Desouky, D. \& Allam, H. (2017). Occupational stress, anxiety and depression among Egyptian teachers. Journal of Epidemiology and Global Health, 7 (3), 191-198.

Di Domenico, M. \& Lynch, P.A. (2007). Host/Guest encounters in the commercial home. Leisure Studies, 26(3), 321-338.

Driessen, E., Hegelmaier, L.M., Abbass, A.A., Barber, J.P., Dekker, J.J., Van, H.L., Jansma, E.P. and Cuijpers, P. (2015). The efficacy of short-term psychodynamic psychotherapy for depression: A meta-analysis update. Clinical psychology review, 42, 1-15.

Economou, M., Madianos, M., Peppou, L.E., Patelakis, A. \& Stefanis, C.N. (2013). Major depression in the Era of economic crisis: A replication of a cross-sectional study across Greece. Journal of Affective Disorders, 145 (3), 308-314. 
Eysenck, H.J. \& Eysenck, M.W. (1958). Personality and Individual differences. Plenum Publishing.

Filep, S. (2012). Positive psychology and tourism. Handbook of Tourism and quality-of-life research. Dordrecht: Springer.

Filep, S. \& Bereded-Samuel, E. (2012). Holidays against depression? An Ethiopian Australian initiative. Current Issues in Tourism, 15 (3), 281-285.

Fullagar, S. (2008). Leisure practices as counter- depressants: Emotion-work and emotion-play with women's recovery from depression. Leisure Sciences, 30 (1), 35-52.

Freud, S. (1917). Trauer und Melancholie. Internationale Zeitschrift für Ärztliche Psychoanalyse, Leipzig and Vienna: Huggo Heller, 4 (6), 288-301.

Gabbard, G.O. (2017). Long-term psychodynamic psychotherapy: A basic text. American Psychiatric Pub.

Gale, S.D, Berrett, A.N., Erickson, L.D., Brown, B.L. \& Hedges, D.W. (2018). Association between virus exposure and depression in US adults. Psychiatry Research, 261, 73-79.

Gao, J. \& Kerstetter, D.L. (2018). From sad to happy to happier: Emotion regulation strategies during a vacation. Annals of Tourism Research, 69, 1-14

Gao, J., Kerstetter, D., Mowen, A. \& Hickerson, B. (2017). Changes in tourists' perception of well-being based on their use of emotion regulation strategies during vacation. Journal of Travel \& Tourism Marketing.

Gholipour, H. F., Tajaddini, R., Nguyen, J. (2016). Happiness and Inbound tourism. Annals of Tourism Research, 57, 251-253

Gibson, H. \& Yiannakis, A. (2002). Tourist roles: Needs and the life course. Annals of Tourism Research, 29 (2), 358-383

Gilbert, D. \& Abdullah, J. (2004). Holiday taking and the sense of well-being. Annals of Tourism Research, 31 (1), 103-121 
Granados, J.A.T. \& Roux, A.V.D. (2009). Life and death during the Great Depression. Proceedings of the National Academy of Sciences, 106(41), 17290-17295.

Glaser, B.G. \& Strauss A.L. (1967). The Discovery of Grounded Theory: Strategies for Qualitative Research. Chicago: Aldine.

Griffiths, A.W., Wood, A.M. \& Tai, S. (2018). The prospective role of defeat and entrapment in caregiver burden and depression amongst formal caregivers. Personality and Individual Differences, 120, 24-31.

Gujral, S., Aizenstein, H., Reynolds, C.F., Butters, M.A. \& Erickson, K.I. (2017). Exercise effects on depression: Possible neural mechanisms. General Hospital Psychiatry, 49, 210.

Guntrip, H. (1995). Personality structure and human interaction: The developing synthesis of psychodynamic theory. London: Karnac Books.

Healy, D. \& Williams, J.M.C. (1988). Dysrhythmia, dysphoria, and depression: The interaction of learned helplessness and circadian dysrhythmia in the pathogenesis of depression. Psychological Bulletin, 103, 163-178.

Henry, W.P., Strupp, H.H., Schacht, T.E. \& Gaston, L. (1994). Psychodynamic approaches. In: Bergin, A.E. \& Garfield, S.L. (Eds). Handbook of psychotherapy and behavior change. Oxford, England: John Wiley \& Sons.

Hill, M.N. \& Gorzalka, B.B. (2005). Is there a role for the endocannabinoid system in the etiology and treatment of melancholic depression? Behavioural Pharmacology, 16 (5-6), 333-352.

Hollon, S.D., Thase, M.E. \& Markowitz, J.C. (2002). Treatment and prevention of depression. Psychological Science in the Public Interest, 3, 39-77.

Huibers, M.J., de Graaf, L.E., Peeters, F.P. \& Arntz, A. (2010). Does the weather make us sad? Meteorological determinants of mood and depression in the general population. Psychiatry research, 180(2), 143-146.

Ioannidou, H. (2005). Melacholia: The ancient Greek point of view. Athens: Publications Grigori. ISBN 960-333-448-0. 
Jiang, T., Ryan, C. \& Zhang, C. (2018). The spiritual or secular tourist? The experience of Zen meditation in Chinese temples. Tourism Management, 65, 187-199.

Johansson, R. (2019). Internet-based psychodynamic psychotherapy. In Contemporary Psychodynamic Psychotherapy (337-347). Academic Press.

Kalahanis, K. (2013). The Hippocratic theory of juices. Available at: http://pemptousia.com/, https://www.pemptousia.gr/2013/03/i-ippokratiki-theoria-peri-ton-chimon/, $\quad$ accessed: February, 2018.

Kalat, J. W. (2011). Introduction to Psychology, $9^{\text {th }}$ edition, CA: Wadsworth.

Khan, A.Y., Carrithers, J., Preskorn, S.H., Lear, R., Wisniewski, S.R., John Rush, A., Stegman, D., Kelley, C., Kreiner, K., Nierenberg, A.A. \& Fava, M. (2006). Clinical and demographic factors associated with DSM-IV melancholic depression. Annals of Clinical Psychiatry, 18(2), pp.91-98.

Kim, H., Woo, E. \& Uysal, M. (2015). Tourism experience and quality of life among elderly tourists. Tourism Management. 46, 465-476.

Kozhyna, H., Korostiy, V., Hmain, S.\& Mykhaylov, V. (2017). The use of art therapy in complex treatment on the quality of remission in patients with melancholy in major depressive disorder. European Psychiatry, 41 (supplement), s777.

Kroesen, M. \& Handy, S. (2014). The influence of holiday-taking on affect and contentment. Annals of Tourism Research, 45, 89-101.

Lepenies, W., Gaines, J.T. and Jones, D.T. (1992). Melancholy and society. Harvard University Press.

Levi, E., Dolev, T., Colins-Kreiner, N. \& Zilcha-Mano, S. (2019). Tourism and depressive symptoms. Annals of Tourism Research, 74, 191-194.

Li, T.E.\& Chan, E.T.H. (2017). Diaspora tourism and well-being: A eudaimonic view. Annals of Tourism Research, 63, 205-206. 
Loechner, J., Starman, K., Galuschka, K., Tamm, J., Schulte-Korne, G., Rubel, J. \& Platt, B. (2017). Preventing depression in the offspring of parents with depression: A systematic review and meta-analysis of randomized controlled trials. Clinical Psychology Review (corrected proof, as at: 07/02/2018).

Lu, L., 2011. Leisure and depression in midlife: A Taiwanese national survey of middle-aged adults. Journal of Health Psychology, 16 (1), pp.137-147.

Lu, L. \& Hu, C.H. (2005). Personality, leisure experiences and happiness. Journal of Happiness Studies, 6, 325-342.

McCabe, S. \& Johnson, S. (2013). The happiness factor in Tourism: Subjective well-being and Social Tourism. Annals of Tourism Research, 41, 42-65.

McLeod, S. (2017). Psychodynamic approach. Available online: https://www.simplypsychology.org/psychodynamic.html. Accessed: 10/2019.

Mikkelsen, S.S., Tolstrup, J.S., Flachs, E.M., Mortensen, E.L., Schnohr, P. \& FlensborgMadsen, T. (2010). A cohort study of leisure time physical activity and depression. Preventive medicine, 51 (6), 471-475.

Moal-Ulvoas, G. (2017). Positive emotions and spirituality in older travelers. Annals of Tourism Research. 66, 151-158.

Molin, J., Mellerup, E., Bolwig, T., Scheike, T. and Dam, H. (1996). The influence of climate on development of winter depression. Journal of Affective Disorders, 37(2), 151-155.

Morgan, N., Pritchard, A. \& Sedgley, D. (2015). Social tourism and well-being in later life. Annals of Tourism Research, 52, 1-15.

Mulhall, S., Andel, R. \& Anstey, K.J. (2018). Variation in symptoms of depression and anxiety in midlife women by menopausal status. Maturitas, 108, 7-12.

Nawijn, J., Mitas, O., Lin, Y. \& Kerstetter, D. (2013). How do we feel on vacation? A closer look at how emotions change over the course of a trip. Journal of Travel Research, 52 (2), $265-274$ 
Nimrod, G., Kleiber, D.A. \& Berdychevsky, L. (2012). Leisure in Coping with Depression. Journal of Leisure Research, 44:4, 419-449.

Ohmae, S. (2012). The difference between depression and melancholia: two distinct conditions that were combined into a single category in DSM-III, Seishin Shinkeigaku Zasshi, 114 (8), 886- 905 .

Ostow, M. (1996). Myth and Madness: The psychodynamics of anti-Semitism. New York: Routledge.

Ots, T. (1990). The angry liver, the anxious heart and the melancholy spleen. Culture, Medicine and Psychiatry, 14(1), pp.21-58.

Palinkas, L.A. (2003). The psychology of isolated and confined environments. American Psychologist, 58, 353-363.

Palinkas, L.A., Horwitz, S.M., Green, C.A., Wisdom, J.P., Duan, N. \& Hoagwood, K. (2015). Purposeful sampling for Qualitative data collection and analysis in mixed method implementation research. Administration and Policy in Mental Health and Mental Health Services Research, 42 (5), 533-544.

Park, S., Jang, H., Furnham, A. Jeon, M. \& Park S. J. (2018). Beliefs about the causes and treatments for depression and bipolar disorder among South Koreans. Psychiatry Research, 260, 219-226.

Patton, M. (2014). Qualitative Research and Evaluation methods, $4^{\text {th }}$ ed., London: Sage Publications.

Patton, M.Q. (2007). Sampling, qualitative (purposive). The Blackwell Encyclopedia of Sociology.

Perry, P.J. (1996). Pharmacotherapy for major depression with melancholic features: relative efficacy of tricyclic versus selective serotonin reuptake inhibitor antidepressants. Journal of Affective Disorders, 39 (1), 1-6.

Person, C., Tracy, M. \& Galea, S. (2006). Risk factors for depression after a disaster. Journal of Nervous and Mental Disease, 194, 659-666. 
Post, R.J. \& Warden, M.R. (2018). Melancholy, anhedonia, apathy: the search for separable behaviors and neural circuits in depression. Current opinion in Neurobiology, 49, 192200.

Puri, B.K. \& Boyd, H. (2005). The natural way to beat depression: The ground-breaking discovery of EPA to successfully conquer depression, Hodder Paperback. ISBN-10: 0340824972 .

Pyke, S., Hartwell, H., Blake, A. \& Hemmingway, A. (2016). Exploring well-being as a tourism product resource. Tourism Management, 55, 94-105.

Radden, J. ed. (2002). The nature of melancholy: From Aristotle to Kristeva. Oxford University Press, USA.

Rothermund, D. (2002). The global impact of the Great Depression 1929-1939. Routledge.

Rothermundt, M., Arolt, V., Fenker, J., Gutbrodt, H., Peters, M. \& Kirchner, H. (2001). Different immune patterns in melancholic and non-melancholic major depression. European Archives of Psychiatry and Clinical Neuroscience, 251 (2), 90-97.

Ryan, C. (2015). Tourist experience and fulfilment: Insights from positive psychology. Annals of Tourism Research, 52, 195-196.

Sack, R.L., Lewy, A.J., White, D.M., Singer, C.M., Fireman, M.J. and Vandiver, R. (1990). Morning vs evening light treatment for winter depression: evidence that the therapeutic effects of light are mediated by circadian phase shifts. Archives of general psychiatry, 47(4), pp.343-351.

Sarfo, F.S., Jenkins, C., Singh, A., Owolabi, M., Ojagbemi, A., Adusei, N., Saulson, R. \& Ovbiagele, B. (2017). Post-stroke depression in Ghana: Characteristics and correlates. Journal of the Neurological Sciences, 379, 261-265.

Saunders, B., Sim, J., Kingstone, T., Baker, S., Waterfield, J., Bartlam, B., Burroughs, H. \& Jinks, C. (2018). Quality \& Quantity, 52 (4), 1893-1907. 
Schwartz, H.S., 2016. The Pristine Self: Psychodynamics of the Anti-Bullying Movement. Political Correctness and the Destruction of Social Order (5-28). Palgrave Macmillan, Cham.

Semin, G. R. (2007). Grounding communication: Synchrony. In: Kruglanski, A. W., Higgins, E. T. (Eds.), Social psychology: Handbook of basic principles (2nd ed., pp. 630-649). New York, NY: Guilford.

Semin, G. R. \& de Groot, J. H. B. (2013). The chemical bases of human sociality. Trends in Cognitive Sciences, 17, 427-429.

Sharpley, R., \& Jepson, D. (2011), Rural Tourism: A spiritual experience?. Annals of Tourism Research, 38 (1), 52-71.

Shenk, J.W. (1989). Lincoln's melancholy: How depression challenged a president and fueled his greatness. J Consult Clin Psychol, 57, 414-419.

Sloan, D.M., Strauss, M.E. \& Wisner, K.L. (2001). Diminished response to pleasant stimuli by depressed women. Journal of Abnormal Psychology, 110, 488-493.

Smith, M.K.\& Diekmann, A. (2017). Tourism and wellbeing. Annals of Tourism Research. 66, $1-13$.

Stone, M. (2015). The Psychodynamics of Evil. In: Naso, R.C. \& Mills, J. (Eds). Humanizing Evil: Psychoanalytic, Philosophical and Clinical Perspectives. New York: Routledge.

Strauss, A. \& Corbin, J. (1998). Basics of qualitative research. $2^{\text {nd }}$ Edition. Thousand Oakes, CA: Sage Publications.

Suri, H. (2011). Purposeful sampling in qualitative research synthesis. Qualitative Research Journal, 11(2), 63-75.

Trigg, D.J. (2009). A field guide to melancholy. Emotion, Space and Society, 2 (1), p. 75.

Tsuno, N., Besset, A. \& Ritchie, K. (2005). Sleep and Depression. The Journal of Clinical Psychiatry, 66 (10), 1254-1269. 
Uysal, M., Sirgy, M.J., Woo, E., Kim, H.L. (2016). Quality of life (QOL) and well-being research in tourism. Tourism Management, 53, 244-261.

Voigt, C., Brown, G. \& Howat, G. (2011). Wellness tourists: in search of transformation. Tourism Review, 66 (1/2), 16-30.

Weinberg, A., Liu, H., Shankman, S.A. (2016). Blunted neural response to errors as a trait marker of melancholic depression. Biological Psychology, 113, 100-107.

Winograd-Gurvich, C., Fitgerald, P.B., Georgiou-Karistianis, N., Bradshaw, J.L. \& White, O.B. (2006). Negative symptoms: A review of schizophrenia, melancholic depression and Parkinson's disease. Brain Research Bulletin, 70, 312-321.

Yang, Y., Wang, H., Hu, J. \& Hu, H. (2018). Lateral habenula in the pathophysiology of depression. Current Opinion in Neurobiology, 48, 90-96.

Zhao, Y., Munro-Kramer, L., Shi, S., Wang, J., Zhu, X. (2018). A longitudinal study of perinatal depression among Chinese high-risk pregnant women. Women and Birth (Corrected proof, as at: 07/02/2018). 
Figure 1: The coding paradigm: Axial coding themes, process and interrelationship (source: authors)

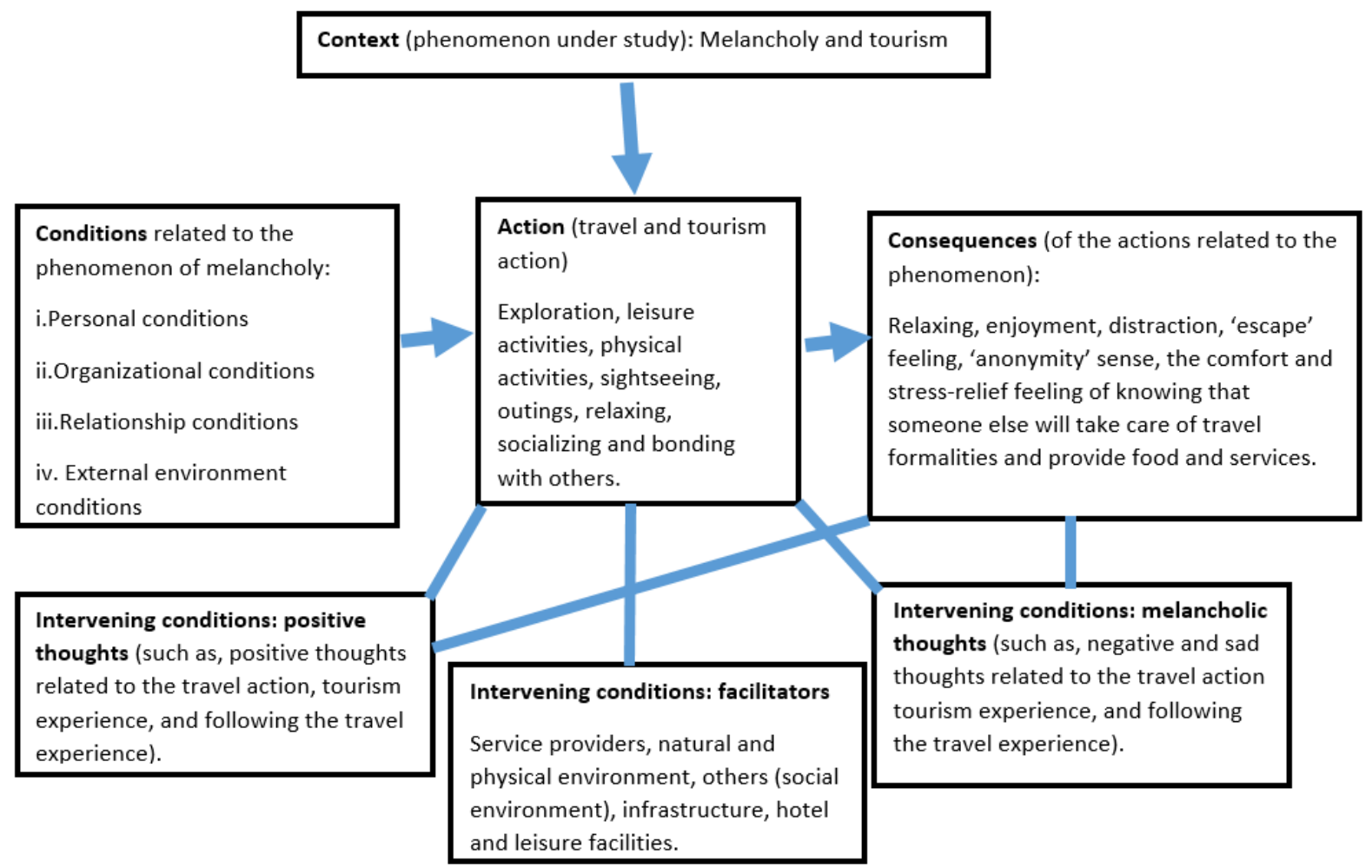


Figure 2: The interplay of tourism with melancholy (source: authors)

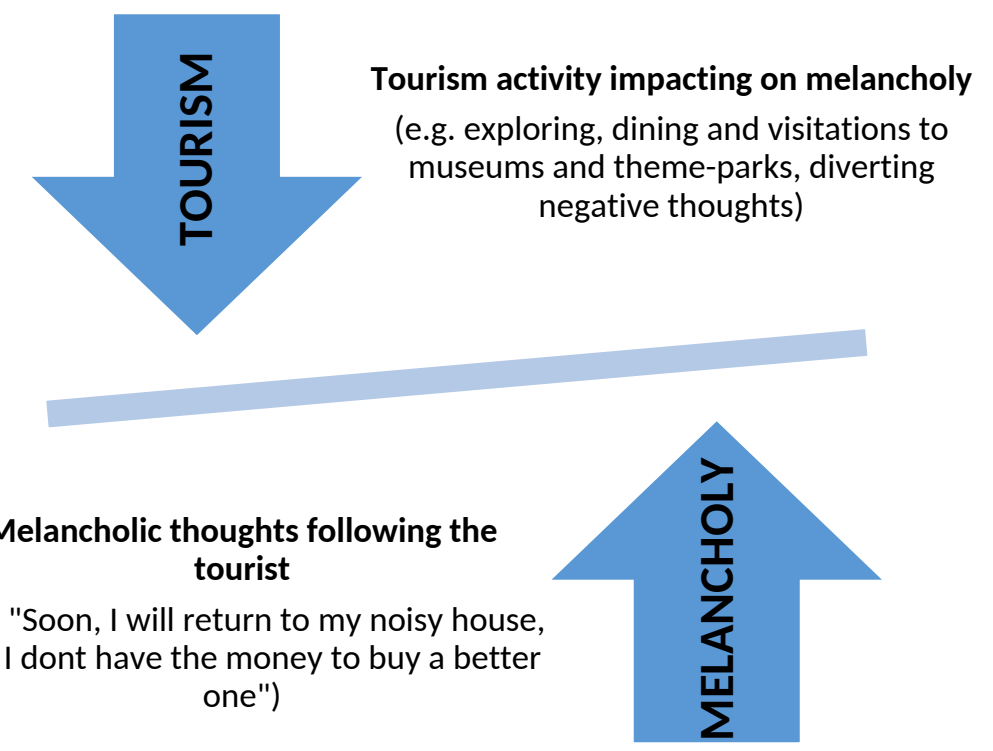


Figure 3: Tourism and melancholy nexus (source: authors)

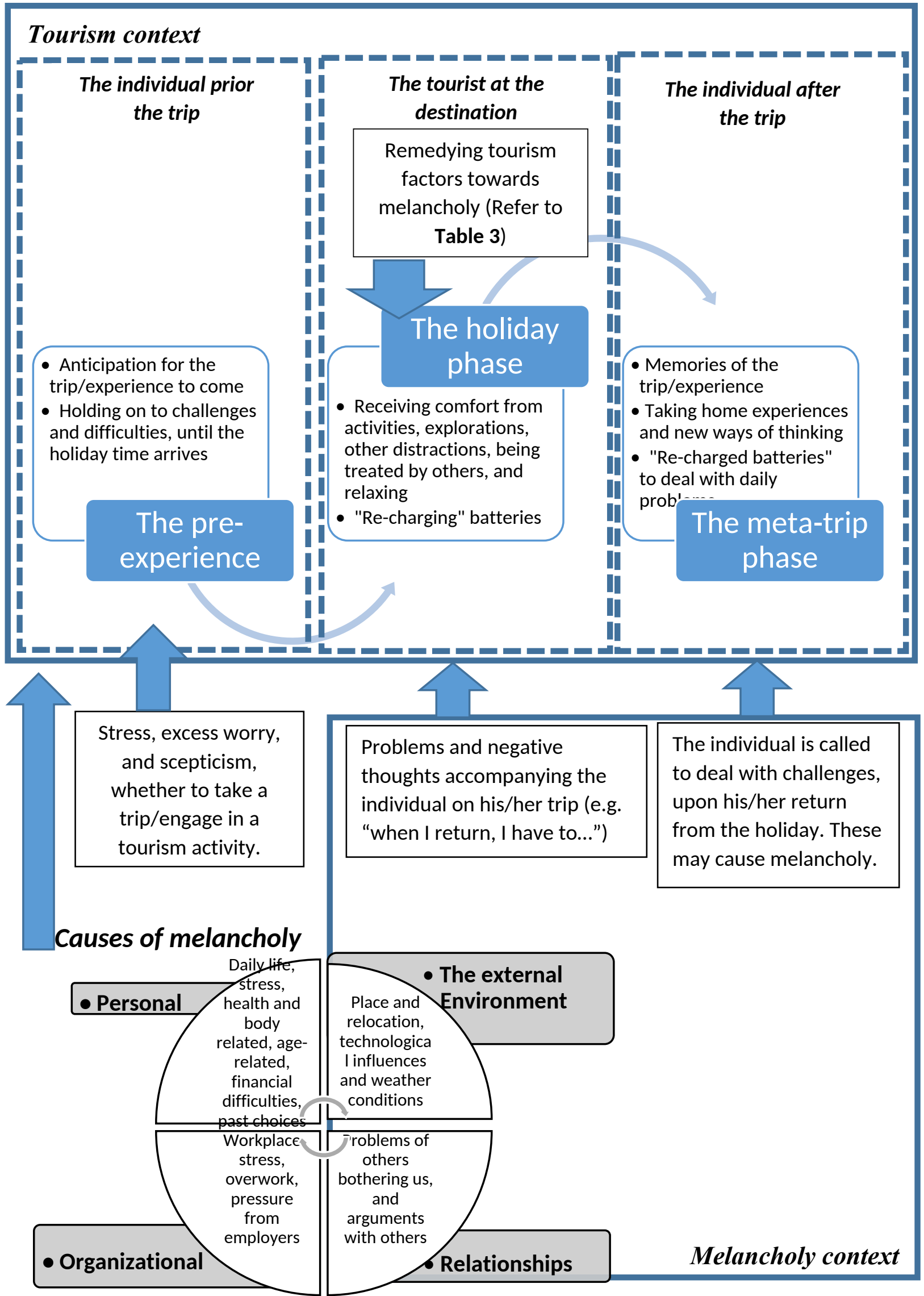


Table 1: Profile of informants

\begin{tabular}{|c|c|c|c|c|}
\hline Pseudonym & Gender & Age & Country & Occupation \\
\hline Albin & M & $20-29$ & Sweden & Employee (private org. \\
\hline Aleksandra & $\mathrm{F}$ & $70+$ & Bulgaria & Retired \\
\hline Amalia & $\mathrm{F}$ & $20-29$ & Cyprus & Employee (private org. \\
\hline Anastasia & $\mathrm{F}$ & $20-29$ & Russia & Student \\
\hline Andria & $\mathrm{F}$ & $40-49$ & Cyprus & Employee (private org. \\
\hline Angelika & $\mathrm{F}$ & $20-29$ & Cyprus & Employee (private org. \\
\hline Anna & $\mathrm{F}$ & $30-39$ & Russia & Employee (public org.) \\
\hline Anthi & $\mathrm{F}$ & $40-49$ & Cyprus & Employee (private org. \\
\hline Ayshe & $\mathrm{F}$ & $30-39$ & Cyprus & Employee (public org.) \\
\hline Chloe & $\mathrm{F}$ & $30-39$ & Australia & Employee (private org. \\
\hline Christos & M & $30-39$ & Cyprus & Employee (private org.) \\
\hline Chrystal & $\mathrm{F}$ & $50-59$ & UK (England) & Employee (private org. \\
\hline Constantinos & M & $40-49$ & Greece & Employee (public org.) \\
\hline Daria & $\mathrm{F}$ & $30-39$ & Russia & Employee (private org. \\
\hline David & $\mathrm{M}$ & $20-29$ & Lebanon & Employee (private org. \\
\hline Denis & $\mathrm{M}$ & $60-69$ & Russia & Employee (private org. \\
\hline Dima & $\mathrm{M}$ & $60-69$ & Russia & Retired \\
\hline Dina & $\mathrm{F}$ & $40-49$ & Cyprus & Employee (private org.) \\
\hline Ella & $\mathrm{F}$ & $30-39$ & UK & Employee (private org. \\
\hline Erin & $\mathrm{F}$ & $50-59$ & UK & Employee (private org.) \\
\hline Ethan & $\mathrm{M}$ & $40-49$ & Australia & Employee (private org. \\
\hline Eva & $\mathrm{F}$ & $70+$ & UK & Retired \\
\hline Gabriela & $\mathrm{F}$ & $30-39$ & Bulgaria & Employee (private org. \\
\hline George & $\mathrm{M}$ & $20-29$ & UK & Unemployed \\
\hline Grace & $\mathrm{F}$ & $40-49$ & UK (N. Irel.) & Employee (public org.) \\
\hline Harry & M & $60-69$ & UK & Employee (private org. \\
\hline Ioana & $\mathrm{F}$ & $20-29$ & Romania & Student \\
\hline Isaac & M & $20-29$ & Australia & Student \\
\hline
\end{tabular}




\begin{tabular}{|c|c|c|c|c|}
\hline Ivan & $\mathrm{M}$ & $60-69$ & Russia & Employee (private org.) \\
\hline James & $\mathrm{M}$ & $50-59$ & UK (N. Irel.) & Retired \\
\hline Jean-Paul & $\mathrm{M}$ & $20-29$ & Lebanon & Employee (private org.) \\
\hline Jonas & $\mathrm{M}$ & $50-59$ & Germany & Employee (public org.) \\
\hline Kate & $\mathrm{F}$ & $20-29$ & Russia & Employee (private org.) \\
\hline Kyriaki & $\mathrm{F}$ & $60-69$ & Cyprus & Retired \\
\hline Laura & $\mathrm{F}$ & $50-59$ & Romania & Employee (private org.) \\
\hline Liam & $\mathrm{M}$ & $50-59$ & Australia & Employee (public org.) \\
\hline Lina & $\mathrm{F}$ & $20-29$ & Germany & Employee (private org.) \\
\hline Lisa & $\mathrm{F}$ & $20-29$ & Cyprus & Employee (private org.) \\
\hline Lucy & $\mathrm{F}$ & $70+$ & UK & Employee (private org.) \\
\hline Luke & $\mathrm{M}$ & $50-59$ & UK & Employee (private org.) \\
\hline Maria & $\mathrm{F}$ & $40-49$ & Cyprus & Employee (private org.) \\
\hline Mary & $\mathrm{F}$ & $40-49$ & Australia & Employee (private org.) \\
\hline Matthew & $\mathrm{M}$ & $60-69$ & UK (England) & Retired \\
\hline Mihaela & $\mathrm{F}$ & $50-59$ & Romania & Employee (private org.) \\
\hline Monica & $\mathrm{F}$ & $30-39$ & Cyprus & Employee (private org.) \\
\hline Natasha & $\mathrm{F}$ & $20-29$ & Russia & Student \\
\hline Noah & $\mathrm{M}$ & $20-29$ & Denmark & Employee (private org.) \\
\hline Nour & $\mathrm{F}$ & $40-49$ & Lebanon & Employee (private org.) \\
\hline Oleg & $\mathrm{M}$ & $70+$ & Russia & Retired \\
\hline Olga & $\mathrm{F}$ & $30-39$ & Cyprus & Employee (private org.) \\
\hline Oliver & $\mathrm{M}$ & $40-49$ & UK (England) & Employee (private org.) \\
\hline Olivia & $\mathrm{F}$ & $70+$ & UK (Scotland) & Retired \\
\hline Oscar & $\mathrm{M}$ & $20-29$ & Sweden & Employee (private org.) \\
\hline Pavlos & $\mathrm{M}$ & $20-29$ & Cyprus & Student \\
\hline Polina & $\mathrm{F}$ & $20-29$ & Russia & Employee (private org.) \\
\hline Socrates & $\mathrm{M}$ & $30-39$ & Cyprus & Employee (public org.) \\
\hline Sophie & $\mathrm{F}$ & $40-49$ & UK & Employee (public org.) \\
\hline Thanos & $\mathrm{M}$ & $40-49$ & Cyprus & Employee (private org.) \\
\hline
\end{tabular}




\begin{tabular}{lllll} 
Thomas & M & $50-59$ & UK & Employee (private org.) \\
Viktoria & F & $20-29$ & Bulgaria & Employee (private org.) \\
\hline
\end{tabular}


Table 2. Causes and paradigms of melancholy (as expressed by informants)

i. Daily life and obligations- House responsibilities, taking care of children or disabled family members, and elderly parents, family and social obligations.

ii. Inability to financially support self and others- Loss of job, job uncertainty.

iii. $\quad$ Stress- "When my plans failed I felt insecure and had melancholy... I went to a doctor who told me it was stress related" (Pavlos, 20-29, Cyprus, Graduate)

iv. Work-related factors- Overwork, culture of organisations and no opportunities to progress. "I didn't like my job and I felt unhappy..." (Socrates, 30-39, Cyprus, Telecommunications officer)

v. $\quad$ Place and physical distance- Relocation. "I was about to leave my country and work in a different country. This change made me feel unhappy but I had to do I,t for my wife" (Jonas, 50-59, Germany, Academic)

vi. Relationships- "At that time, I was having arguments with friends and my boyfriend and then I lost someone special... a close friend. I felt miserable for quite a long time" (Amalia, 20-29, Cyprus, Employee in the private sector)

vii. Others' problems affecting us- "Unfortunately, my son failed his exams and he started taking drugs..." (Luke, 50-59, UK, Accountant)

viii. Health and body related causes- "I was diagnosed with cancer and that caused me depression" (Kyriaki, 60-69, Cyprus, Retired due to health issues).

ix. The loss of loved ones- "... I lost my dad and after six months my mum was diagnosed with dementia..." (Erin, 50-59, UK, Lawyer)

x. Feeling of unhappiness- The general feeling of unhappiness in our lives. "I hated our new life when my mum moved in with my stepdad and I had to go with her. I wanted my family back together" (Daria, 30-39, Russia, Accountant)

xi. Technological influences- "It is sad... We are becoming slaves of technology, and this causes us a lot of pressure and stress" (Matthew, 60-69, UK, Retired)

xii. Bereavement and age- People becoming more aware of their mortality.

xiii. Weather related- "Weather in N. Ireland isn't good. We have grey skies... with a few days of good sunny warm weather..." (James, 50-59, UK, Retired bank officer)

xiv. Past choices in life- "I didn't know whether I chose the right career path and that caused me melancholy..." (Kate, 20-29, Russia, Hotel employee) 
Table: Travel characteristics of informants

Destination

Number of informants

Island destination $\quad 36$

Non-island destination 24

Total 60

Specific destination

Number of informants

Cyprus

Greek islands (e.g. Crete, Poros and Skopelos)

U.K.

France

4

Italy

3

Greece (mainland)

Germany

Spain (mainland)

Spain (island- Majorca)

U.S.A.

U.S.A. (Hawaii)

Austria

Bulgaria

Fiji Islands

France (island- Corsica)

India

Singapore

Thailand (island- Phuket)

Turkey 1 
With company* 58

$\underline{\text { Alone }}$ 2

$\underline{\text { Total }}$ 60

*Note: Informants traveling with company (i.e. partners, family or friends) and/or visiting family or/and friends at the destination. 
Theme 'a': Diversion, distraction, pleasure and escape factors (exploration, physical and mental/spiritual activities, and outings.

- Leisure and other activities- Having fun, shopping books, visiting markets, exercising, swimming and snorkelling.

- Exploring- Familiarizing with other cultures and road trips. "I think sightseeing, was the most powerful experience..." (Anna, 30-39, Russia, Lecturer). “What made me feel much better was meeting different people, visiting places such as the Sagrada Familia [Barcelona], and of course drinking sangria”. (Isaac, 20-29, Australia)

- Hotel and outings- Having a nice breakfast, being offered good service, going out for dinner, enjoying great food, drinking cocktails, socializing with friends while having meals, going out to theatres/concerts. "I love France, and I was there for the fifth time. I enjoyed my time there. I saw places I loved visiting ... I had coffee at quiet places and nice food. I had the chance to get away from everything that reminded me of my problems" (Erin, 50-59, UK)

- The "escape" feeling- "I'm a slave to the computer, checking staff, answering emails... we do not $f^{* *}$ need it! It's good to be away, to escape, to listen to the waves..." (Matthew, 60-69, UK, Retired).

- Distraction- "Going for holidays with friends always eases the symptoms, because the mind gets distracted from the everyday problems, which I tend to associate with particular spaces quite a lot ... Whenever I go away for holidays, it is always the case that my melancholy rates are reduced" (Olga, 30-39, Cyprus)

Theme 'b': A minimum of physical, psychological, and mental effort (relaxing, being treated by others and receiving service, being supported by infrastructure)

- Relaxing, or the feeling of doing "nothing"- Having others (e.g. employees) taking care of us, lying by the pool, having spa treatments, seaside/forest walks and reading books. “... I guess, the facilities offered [of a five-star property] really do make a difference. It's an opportunity for some pampering, which I would consider relatively therapeutic." (Sophie, 40-49, UK) 


\section{Theme 'c': The choice between isolation and socializing/bonding with other people}

- The anonymity factor- "I find the sense of anonymity abroad, comforting" (Olga, 3039, Cyprus, Academic).

- Socializing and bonding- Spending time with family, reconnecting with friends, catching up and laughing. "Talking with strangers and the people of the island, can make you listen other lifestyles and opinions about life, which makes you, see life from another perspective" (Ayshe, 30-39, Cyprus, Librarian)

\section{Theme 'd': Weather conditions with a comforting effect (for example, sunshine or snow)}

- Enjoying the weather- For instance, being out in the sun and walks by the sea. "Just coming to Cyprus lifts my mood ... I feel safe and at home here ... The weather is fabulous, and aches and pains improve. I love the beaches and walking here”. (James, 50-59, Northern Ireland) 